\title{
The Relationship Between Psychosocial Factors and Adherence to Treatment in Men, Premenopausal and Menopausal Women with Type 2 Diabetes Mellitus
}

\author{
Olga Estefania Escobar \\ Florez (ID) ' \\ Gabriela Aquilera' \\ Jose Maria De la \\ Roca-Chiapas (D) ${ }^{2}$ \\ Maciste Habacuc Macías \\ Cervantes' \\ Ma Eugenia Garay-Sevilla' \\ 'Department of Medical Sciences, \\ Division of Health Science, University of \\ Guanajuato, Campus León, Obregón, \\ León, Gto, C.P. 37320, México; \\ ${ }^{2}$ Department of Psychology, Division of \\ Health Science, University of Guanajuato, \\ Campus León, León, Gto, C.P. 37670 , \\ México
}

Correspondence: Ma Eugenia Garay-Sevilla Department of Medical Sciences, Division of Health Science, University of Guanajuato, Campus León, 20 de enero 929, Colonia, Obregón, León, Blvd. Puente Milenio I00I Fracción del Predio San Carlos, Gto, C.P. 37320, México

Email marugaray_2000@yahoo.com
Introduction: Type 2 Diabetes Mellitus (T2DM) is a chronic disease that begins in adulthood, and is caused by multiple factors. The onset of menopause involves changes that predispose women to the development of T2DM, which can worsen if the adherence to treatment is inadequate due to psychosocial factors or medications. The present study aims to describe the psychosocial factors that may affect adherence to treatment among men and premenopausal and menopausal women with T2DM.

Methods: This was a cross-sectional study of 96 patients with T2DM, who were divided into three groups: 1) men $(n=32)$; 2) premenopausal women $(n=32)$; and 3) menopausal women $(n=32)$. Somatometric and metabolic control data were obtained. Adherence to treatment and psychosocial factors were evaluated: social support, belief in conventional medicine, disease denial, and depressive symptoms.

Results: Adherence to medication had a negative correlation with depressive symptoms in men $(\mathrm{p}<0.001)$ and menopausal women $(\mathrm{p}<0.021)$. Dietary adherence had a positive correlation with belief in conventional medicine in men $(\mathrm{p}<0.037)$ and premenopausal women $(\mathrm{p}<0.029)$.

Conclusion: Medication adherence in men and menopausal women was correlated with fewer depressive symptoms. Adherence to diet in men and premenopausal women was correlated with greater belief in conventional medicine. The results show the diversity of psychosocial factors among the groups that must be addressed in order to improve adherence.

Keywords: diet, medication, conventional medicine, depressive symptoms

\section{Introduction}

Type 2 diabetes mellitus (T2DM) is a chronic disease characterized by the progressive loss of insulin secretion by $\mathrm{B}$ cells. It has multiple causes, and requires adequate adherence to treatment, including pharmacology and a change in lifestyle. ${ }^{1,2}$ Adherence to treatment is influenced by patients' behaviors and beliefs regarding following the instructions prescribed for their disease. ${ }^{3}$ A review study showed that the prevalence of adherence ranged from 38.5 to $93.1 \%$ and that depression and the cost of medication are modifiable predictors of adherence behavior. ${ }^{4}$ Biochemical and clinical parameters improve if they are actively controlled by medical personnel, favoring adherence. ${ }^{5}$ It has also been observed that self-care activities and adherence to medication are relevant for improving the results in DM management. ${ }^{6,7}$ 
There are some barriers which can produce resistance in treatment continuation; they can be classified as patientrelated factors (psychosocial factors), such as cognitive difficulties, emotional concerns, depression, and belief in medications. Another category involves barriers regarding medication prescriptions, such as fear of taking them, the complexity of the regimen, among others. ${ }^{8}$ Social support and self-rated health suggest that interventions in these two variables are valuable to increase adherence to medication among this population. ${ }^{9}$ In another study, it was observed that patients with depression had high levels of glucose and HbAlc, indicating poor glycemic control and, therefore, decreased adherence. ${ }^{10}$ In patients with T2DM, it has been observed that the main reasons for refusing insulin therapy are denial of the disease and denial of the failure of oral medications, due to the chronic nature of the disease and the appearance of complications, some patients do not care about their current medical condition. ${ }^{11}$

There are some other factors that can have an impact on adherence to treatment in T2DM, such as the patient's gender and disease perception. A study of male patients in whom disease was considered more difficult to control revealed an association with decreased adherence and lower knowledge about the disease. ${ }^{12}$ On the other hand, it has been reported that males of older age groups, who take several other medications and frequently visit their doctor, are associated with better adherence; ${ }^{13}$ and in middle-aged groups, self-care and lifestyle activities were deficient, but the absence of joint pain and fewer complaints about anxiety and depressive symptoms were associated with good adherence. $^{14}$

Women have a higher risk of developing T2DM than men, ${ }^{15}$ the most common diagnosis age being between 50 and 69 years. $^{16}$ In women, phenotypic and metabolic changes occur due to the menopausal transition that predisposes them to the development of T2DM. ${ }^{17-19}$ Menopause is a state of relative androgen excess due to a decrease in sex hormone binding globulin (SHBG); these hormonal changes increase insulin resistance. ${ }^{20}$ Depression has been found to be associated with poorer glycemic control and poorer emotional functioning in postmenopausal women. ${ }^{21}$ There is more research on adherence to treatment of T2DM in men with regard to the barriers to adherence to treatment related to psychosocial factors, because as a group, they are hormonally more stable than women. There is not much information on premenopausal or menopausal women with T2DM, who represent a high-risk group for this type of medical condition, in which the psychosocial context must be considered. For this reason, the objective of the present study is to evaluate psychosocial factors and their relationship with adherence to treatment in men, premenopausal and menopausal women with T2DM.

\section{Materials and Methods}

In a cross-sectional design, 96 patients with T2DM were studied, which were recruited from the health clinics of the Secretary of Health in Guanajuato, Mexico and patients attending the Department of Medical Science, University of Guanajuato. We selected three groups of patients: 1) men $(\mathrm{n}=32) ; 2)$ premenopausal women $(\mathrm{n}=32)$; and 3$)$ menopausal women $(n=32)$.

\section{Inclusion Criteria}

The inclusion criteria were as follows: age between 40-64 years; more than 5 years since the diagnosis of T2DM; more than 6 years of education; no history of vascular disease, stroke, psychiatric or neurological disease, visual or hearing impairment, or major depressive disorder; no consumption of alcohol or tobacco; no beta-blocker, neuroleptic, vitamin E, or hormone replacement therapy.

\section{Questionnaire Data Collection}

Patients answered a questionnaire consisting of direct questions asked by an investigator, that included the following items:

\section{General Data}

age; years since T2DM diagnosis and education (years).

\section{Somatometric Variables}

Weight $(\mathrm{kg})$, height $(\mathrm{cm})$, and body mass index (BMI) were obtained according to standard techniques. ${ }^{22}$

Systolic and diastolic blood pressure were measured while the subjects were sitting.

\section{Adherence to Treatment}

Dietary and medication adherence were evaluated separately using a previously reported questionnaire. ${ }^{23}$ Dietary adherence was evaluated with eight questions, which score ranged from 8 to 40 on a Likert-type scale. Adherence to medication was evaluated with three questions, and the results ranged from 3 to 15 on a Likert-type scale. Higher scores indicated better adherence to treatment. Validity of the questionnaire was tested in Mexican 
population in a pilot study applied to 20 patients with $\mathrm{T} 2 \mathrm{DM}$ and previously published by Garay-Sevilla et al. ${ }^{23}$

\section{Psychosocial Evaluation}

\section{Social Support}

Social support was evaluated based on the patient's perception of the support they received from their family and friends to comply with the treatment for T2DM. ${ }^{23}$ This instrument was validated and used in previous works by Garay-Sevilla et al. ${ }^{23,26}$

\section{Belief in Conventional Medicine}

This was assessed with an instrument where the construct validity was tested in a pilot study on twenty patients with T2DM, analyzing intrinsic consistency with a correlation matrix; used and published previously by Garay-Sevilla et al. ${ }^{24}$ It included 12 items regarding the most frequent objections to following medical instructions as mentioned by patients who chose alternative forms of treatment. Scores ranged from 12 to 60 . Higher scores indicated a stronger belief in conventional medicine.

\section{Disease Denial Assessment}

We used the Levine's Disease Denial Scale ${ }^{25}$ previously modified, validated and reported by Garay-Sevilla et al. ${ }^{26}$ This measures 24 different expressed forms of denial of illness; in the clinical construct, the interviewer asked probing questions regarding a variety of the patient's attitudes, concerns, emotional reactions, and overt behavior concerning his illness. Denial levels are scored in terms of the degree to which patients minimize or distort risk in order to avoid dealing with the illness. The range of scores was from 0 to 144 .

\section{Depressive Symptoms}

These were evaluated with 14 items: eight on mood; three on sleeping; and three on non-specific symptoms. The range of scores was 0 to 41 , with higher scores indicating greater depressive symptomatology. This instrument was validated and used previously in Mexican population by Huerta Franco et al. ${ }^{27}$

\section{Metabolic Control}

A venous blood sample was obtained after $12 \mathrm{~h}$ of fasting. Serum was processed the same day and used for measurement of glucose (GOD-PAP enzymatic method, purchased from Lakeside) and $\mathrm{HbAlc}$ determination by highperformance liquid chromatography (Sigma, St. Louis, MO). Lipid, total cholesterol, low-density lipoprotein
(LDL-C), high-density lipoprotein (HDL-C), very lowdensity lipoprotein (VLDL-C), and triglyceride profiles were assessed using enzymatic methods.

\section{Ethical Considerations}

The present study was conducted in accordance with the Declaration of Helsinki, and the Nuremberg Code. The protocol was approved by the ethics committee of the Department of Medical Science of the University of Guanajuato (CEDCM-05), and all participants signed informed consent forms.

\section{Statistical Analysis}

Distribution analysis was performed with the KolmogorovSmirnov test. Parametric variables are presented as the mean \pm standard deviation (SD), and non-parametric variables are presented as the median (interquartile range). Differences between the groups of men and premenopausal and menopausal women were assessed using the ANOVA test for parametric variables and the Kruskal-Wallis test for non-parametric variables along with the Tukey post hoc test. Spearman correlation was used to assess adherence to medication and diet with psychosocial factors.

All statistics were performed with the Statistica V. 7.0 (StatSoft, Inc), and $p<0.05$ was considered significant.

\section{Results}

The general characteristics of the data corresponding to the groups of men and premenopausal and menopausal women are shown in Table 1. Menopausal women were older than men $(\mathrm{p}<0.001)$ and premenopausal women ( $p$ $<0.0001)$. Metabolic control was similar in the three study groups as was adherence to treatment. We found a significant difference in social support between men and menopausal women $(\mathrm{p}<0.02)$ and in depressive symptoms between men and menopausal women $(p<0.015)$. In general, men had greater social support than menopausal women, and menopausal women had more depressive symptoms than men. A marginal difference was observed for disease denial, which was greater among men.

Table 2 shows the correlations between adherence to medication and psychosocial factors among the three groups. Adherence to medication had a negative correlation with depressive symptoms among men $(p<0.001)$ and menopausal women $(p<0.021)$; no association was found for the other psychosocial factors. Dietary adherence (Table 3) had a positive correlation with belief in 


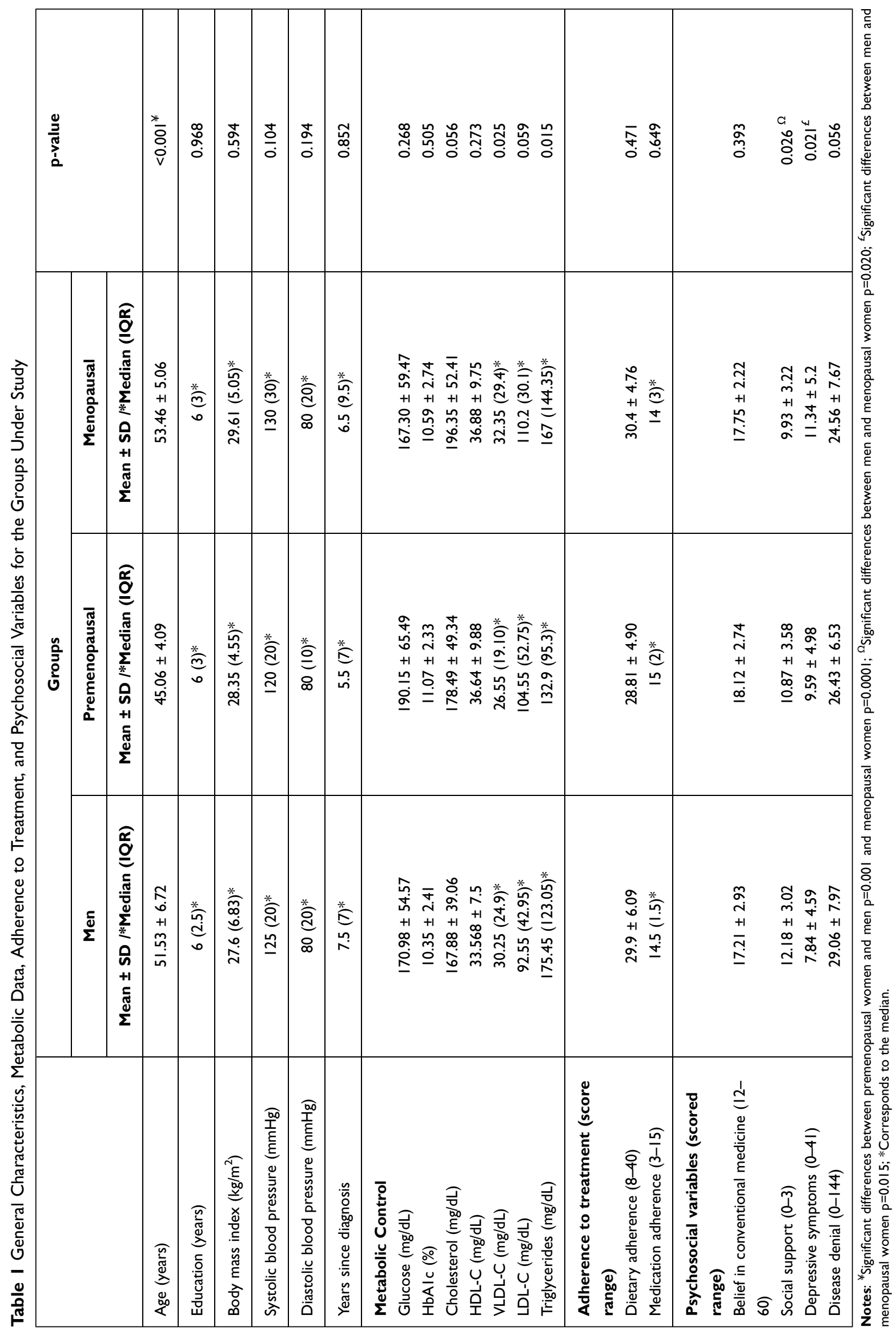


Table 2 Correlations Between Medication Adherence and Psychosocial Factors in Men and Premenopausal and Menopausal Women

\begin{tabular}{|l|c|c|c|c|c|c|}
\hline \multirow{2}{*}{ Psychosocial Factors } & \multicolumn{3}{|c|}{ Medication Adherence } \\
\cline { 2 - 7 } & \multicolumn{2}{|c|}{ Men } & \multicolumn{2}{c|}{ Premenopausal } & \multicolumn{3}{c|}{ Menopausal } \\
\cline { 2 - 7 } & Spearman R & p-value & Spearman R & p-value & Spearman R & p-value \\
\hline Belief in conventional medicine & 0.233 & 0.197 & -0.005 & 0.975 & 0.264 & 0.150 \\
Social support & -0.145 & 0.426 & 0.146 & 0.432 & 0.327 & 0.072 \\
Depressive symptoms & -0.556 & $<0.001$ & -0.019 & 0.917 & -0.410 & $\mathbf{0 . 0 2 1}$ \\
Denial of disease & -0.072 & 0.694 & -0.126 & 0.499 & 0.074 & 0.690 \\
\hline
\end{tabular}

Note: bold values indicate values with statistical significance, with a value of $p<0.05$.

Table 3 Correlations Between Dietary Adherence and Psychosocial Factors in Men and Premenopausal and Menopausal Women

\begin{tabular}{|l|c|c|c|c|c|c|}
\hline \multirow{2}{*}{ Psychosocial Factors } & \multicolumn{3}{|c|}{ Dietary Adherence } \\
\cline { 2 - 7 } & \multicolumn{2}{|c|}{ Men } & \multicolumn{2}{c|}{ Premenopausal } & \multicolumn{3}{c|}{ Menopausal } \\
\cline { 2 - 7 } & Spearman R & p-value & Spearman R & p-value & Spearman R & p-value \\
\hline Belief in conventional medicine & 0.369 & $\mathbf{0 . 0 3 7}$ & 0.385 & $\mathbf{0 . 0 2 9}$ & 0.135 & 0.460 \\
Social support & 0.209 & 0.250 & 0.133 & 0.466 & 0.230 & 0.204 \\
Depressive symptoms & -0.238 & 0.187 & -0.147 & 0.421 & -0.219 & 0.227 \\
Disease denial & -0.322 & 0.071 & -0.006 & 0.972 & -0.249 & 0.168 \\
\hline
\end{tabular}

conventional medicine among men $(\mathrm{p}<0.037)$ and premenopausal women $(\mathrm{p}<0.029)$.

In an additional analysis of correlations, older males showed lower HbA1c and disease denial $(r=-0.357$, $\mathrm{p}<0.044 ; \mathrm{r}=-0.444, \mathrm{p}<0.010$, respectively), and premenopausal women received less social support $(r=-0.396$, $\mathrm{p}<0.024)$.

\section{Discussion}

The main findings of this study show that there are relationships between some psychosocial factors that are dependent on gender and female hormonal stages, and adherence to treatment in T2DM. In men and menopausal women, greater adherence to medication correlates with less depressive symptomatology. Among men and premenopausal women, a greater belief in conventional medicine is related to better adherence to diet.

Older menopausal women perceive less social support, which can predispose them to more menopausal and depressive symptoms. ${ }^{28}$ Premenopausal and menopausal women experience phases of large hormonal fluctuations in estradiol and progesterone levels, which has been shown to correlate with physical and psychological symptoms and has been referred to as "complaints of menopause" in several studies. ${ }^{29}$ At the social level, this has been suggested to influence the development of a negative attitude towards menopause, which can be associated with a lower perception of social support as compared to men. ${ }^{30}$

In the present study, social support did not show a significant relationship with adherence to treatment in any of the groups. This may be reflected in the social context faced by both sexes, such as the high rates of femicide in Mexico (10 women per day) that may influence the ability of women to recognize the need to seek social support in vulnerable situations, such as in the setting of a chronic disease. $^{31}$ This is supported by another study which found that poor social support in menopausal women was related to physical/sexual violence and drug use. ${ }^{32}$ In another research, it has been observed that greater social support is not associated with a decrease in symptoms of menopause, suggesting that perceived stress has a greater effect and is a variable that might influence adherence to treatment. ${ }^{33}$ In men, the presence of impulsive aggressiveness is common, affecting executive functioning and therefore decision-making and causing them to reject social support or improvements in their medical and social condition. ${ }^{34}$ This is in contrast to a study from Chile in which men had greater social support than women and the average age was 63 years. ${ }^{9}$

In the present study, it was observed that menopausal women showed greater depressive symptoms and less social support than men. Mild depressive symptoms usually appear in the premenopausal phase and should 
be monitored clinically, as they can evolve into a major depressive disorder. In this case, menopause is not considered a high-risk phase for psychiatric illness; however, it can be a time of psychological stress that, if not properly monitored, can evolve into a mood disorder, such as depression. ${ }^{35}$ In the scientific literature, there is a debate regarding climacteric stages and their association with emotional state. In some studies, premenopausal women show greater depressive symptoms than postmenopausal women. ${ }^{36}$ In other studies, menopause has been shown to increase the risk of developing major depression. ${ }^{37}$ Adaptive control is important for adequate biopsychosocial functioning with which to respond to environmental demands, so it is relevant to establish interventions based on coping strategies and emotional regulation, specifically involving cognitive reappraisal and expressive suppression. This way, the level of adherence to treatment may be improved. ${ }^{38}$

Among men and premenopausal women, belief in conventional medicine was related to better adherence to diet, consistent with a prior study in which belief in conventional medicine was correlated with adherence to treatment as well as other factors, such as schooling, socioeconomic status, and medical care. ${ }^{24}$ This is in contrast to a study in which $41 \%$ of women reported dissatisfaction with conventional medicine and preferred alternative medicine. ${ }^{39}$

Disease denial did not show a significant relationship, which contrasts with a study conducted on coping and beliefs in chronic disease in which men scored high in denying their condition. ${ }^{40}$ Regarding the above, some theorists specify that the initial response to a clinical diagnosis is denial and that this defense mechanism helps to cope with the impact of the diagnosis; however, if this response is maintained, it can be detrimental to the physical and psychological well-being of the patient. ${ }^{41}$ The reasons for this difference may be due to the size of the sample, in addition to the fact that disease denial was related to age in men (ie, older men showed less disease denial), thereby generating better adherence not directly related to this psychosocial factor. In addition, men had better glycemic control with age, correlating with better adherence to treatment, which is consistent with studies in which men had better glycemic control than women, which may be due to differences in glucose homeostasis, response to treatment and psychological factors. ${ }^{42}$

The present study has some limitations, among which are a small sample size and a cross-sectional design, so causality regarding the variables may not be reflected.
Likewise, the different climacteric stages between menopause and post-menopause were not addressed, so there might be an obvious difference between the groups. The same is true for men as they could be in andropause, which could lead to significant variability. For future studies, we recommend evaluating emotional regulation strategies.

\section{Conclusion}

Medication adherence in men and menopausal women was correlated with fewer depressive symptoms, and adherence to diet in premenopausal women and men was correlated with greater belief in conventional medicine. Our results reveal areas in which psychological interventions based on coping strategies and emotional regulation could help improve adherence to treatment in patients with T2DM. However, more studies are required with a larger sample size and a longitudinal design that makes it possible to explain or predict adherence to treatment.

\section{Acknowledgments}

We express gratitude to all study participants and the University of Guanajuato.

\section{Funding}

This research was funded with resources from the University of Guanajuato.

\section{Disclosure}

The authors report no conflicts of interest in this work.

\section{References}

1. American Diabetes Association. 2. Classification and diagnosis of diabetes. Stand Med Care Diabetes. 2019;18-22. doi:10.2337/dc19S002

2. Cramer JA. A systematic review of adherence with medications for diabetes. Diabetes Care. 2004;27(5):1218-1224. doi:10.2337/ diacare.27.5.1218

3. Vrijens B, De Geest S, Hughes DA, et al. A new taxonomy for describing and defining adherence to medications. Br J Clin Pharmacol. 2012;73 (5):691-705. doi:10.1111/j.1365-2125.2012.04167.x

4. Krass I, Schieback P, Dhippayom T. Adherence to diabetes medication: a systematic review. Diabet Med. 2015;32(6):725-737. doi:10.1111/dme.12651

5. Yarkova NA, Borovkov NN. Adherence to the treatment in patients with type 2 diabetes mellitus and ways to its optimization. Klin Med. 2016;94(9):688-692. doi:10.18821/0023-2149-2016-94-9-688-692

6. Jannoo Z, Mamode Khan N. Medication adherence and diabetes self-care activities among patients with Type 2 diabetes mellitus. Value Heal Reg Issues. 2019;18:30-35. doi:10.1016/j.vhri.2018.06.003

7. Mogre V, Johnson NA, Tzelepis F, Shaw JE, Paul C. A systematic review of adherence to diabetes self-care behaviours: evidence from low- and middle-income countries. $J$ Adv Nurs. 2019;75 (12):3374-3389. doi:10.1111/jan.14190 
8. Sankar UV, Lipska K, Mini GK, Sarma PS, Thankappan KR. The adherence to medications in diabetic patients in rural Kerala, India. Asia-Pacific J Public Heal. 2015;27(2):513-523. doi:10.1177/ 1010539513475651

9. Poblete F, Lantadilla NB, Sapag JC, et al. Social support, self-rated health, treatment adherence and effectiveness in patients with type II diabetes and hypertension. Rev Med Chil. 2018;146(10):1135-1142. doi:10.4067/S0034-98872018001001135

10. De La Roca-chiapas JM, Hernández-González M, Candelario M, et al. Association between depression and higher glucose levels in middle-aged Mexican patients with diabetes. Rev Investig Clin. 2013;65(3):209-213.

11. Salehi S, Majdzadeh R, Mirmiranpour H, Rajab A, Esteghamati A, Nakhjavani M. Barriers to initiation of insulin therapy in poorly controlled type 2 diabetes based on self-determination theory. East Mediterr Heal J. 2020;26(11):1331-1338. doi:10.26719/emhj.20.027

12. Pentzek M, Santos S, Wollny A, et al. Which patients with type 2 diabetes mellitus are perceived as "difficult" by general practitioners? Prim Care Diabetes. 2019;13(4):353-359. doi:10.1016/j.pcd.2019.01.001

13. Horii T, Momo K, Yasu T, Kabeya Y, Atsuda K. Determination of factors affecting medication adherence in type 2 diabetes mellitus patients using a nationwide claim-based database in Japan. PLoS One. 2019;14(10):1-12. doi:10.1371/journal.pone.0223431

14. Marinho FS, Moram CBM, Rodrigues PC, Leite NC, Salles GF, Cardoso CRL. Treatment adherence and its associated factors in patients with type 2 diabetes: results from the Rio de Janeiro type 2 diabetes cohort study. J Diabetes Res. 2018;2018:8. doi:10.1155/ 2018/8970196

15. Huxley R, Barzi F, Woodward M. Excess risk of fatal coronary heart disease associated with diabetes in men and women: meta-analysis of 37 prospective cohort studies. $\mathrm{Br}$ Med J. 2006;332(7533):73-78. doi:10.1136/bmj.38678.389583.7C

16. Secretaría de Salud de México. Encuesta Nacional de Salud y Epidemiología de Medio Camino 2016. Informe Final de Resultados; 2016. Available from: https://www.gob.mx/cms/uploads/attachment/file/ 209093/ENSANUT.pdf. Accessed November 25, 2021.

17. Stavroula AP, Nikolaos P. Type 2 diabetes mellitus and menopausal hormone therapy: an update. Diabetes Ther. 2019;10(6):2313-2320. doi:10.1007/s13300-019-00695-y

18. Mauvais-Jarvis F, Manson JAE, Stevenson JC, Fonseca VA. Menopausal hormone therapy and type 2 diabetes prevention: evidence, mechanisms, and clinical implications. Endocr Rev. 2017;38 (3):173-188. doi:10.1210/er.2016-1146

19. Szmuilowicz ED, Stuenkel CA, Seely EW. Influence of menopause on diabetes and diabetes risk. Nat Rev Endocrinol. 2009;5:553-558. doi:10.1038/nrendo.2009.166

20. Paschou SA, Anagnostis P, Goulis DG, Lambrinoudaki I. Androgen excess and post-reproductive health. Maturitas. 2018;115:115-116 doi:10.1016/j.maturitas.2018.04.005

21. Wagner JA, Tennen H. History of major depressive disorder and diabetes outcomes in diet- and tablet-treated post-menopausal women: a case control study. Diabet Med. 2007;24(2):211-216. doi:10.1111/j.1464-5491.2007.02044.x

22. Centers for Disease Control and Prevention. Anthropometry procedures manual. In: National Health and Nutrition Examinatory Survey (NHANES); 2007.

23. Garay-Sevilla ME, Nava LE, Malacara JM, et al. Adherence to treatment and social support in patients with non-insulin dependent diabetes mellitus. $J$ Diabetes Complications. 1995;9(2):81-86. doi:10.1016/1056-8727(94)00021-F

24. Garay-Sevilla ME, Malacara JM, González-Parada F, Jordán-Ginés L. The belief in conventional medicine and adherence to treatment in non-insulin-dependent diabetes mellitus patients. J Diabetes Complications. 1998;12(5):239-245. doi:10.1016/S10568727(97)00075-5
25. Levine J, Warrenburg S, Kerns R, et al. The role of denial in recovery from coronary heart disease. Psychosom Med. 1987;49:109-117. doi:10.1097/00006842-198703000-00001

26. Garay-Sevilla ME, Malacara JM, Gutiérrez-Roa A, González E. Denial of disease in Type 2 diabetes mellitus: its influence on metabolic control and associated factors. Diabet Med. 1999;16:238-244. doi:10.1046/j.1464-5491.1999.00033.x

27. Huerta MR, Mena A, Malacara JM, et al. Symptoms at perimenopausal period: its association with attitudes toward sexuality, life-style, family function and FSH levels. Psychoneuroendocrinology. 1995;20:135-148. doi:10.1016/0306-4530(94)00046-d

28. Zhao D, Liu C, Feng X, Hou F, Xu X, Li P. Menopausal symptoms in different substages of perimenopause and their relationships with social support and resilience. Menopause. 2019;26(3):233-239. doi:10.1097/GME.0000000000001208

29. Willi J, Süss H, Ehlert U. The Swiss Perimenopause Study - study protocol of a longitudinal prospective study in perimenopausal women. Women's Midlife Heal. 2020;6(5). doi:10.1186/s40695-02000052-1

30. Nülüfer E, Mehtap G. Relationship between perceived social support and attitudes towards menopause among women and affecting factors. Middle Black Sea J Heal Sci. 2018;4(2):7-18. doi:10.19127/mbsjohs.417940

31. Rodríguez Pedraza Y. La feminización de la pandemia COVID19 en México. Rev Venez Gerenc. 2020;25(90):1-20. doi:10.37960/rvg. v25i90.32386

32. Duff PK, Money DM, Ogilvie GS, et al. Severe menopausal symptoms associated with reduced adherence to antiretroviral therapy among perimenopausal and menopausal women living with HIV in Metro Vancouver. Menopause. 2018;25(5):531-537. doi:10.1097/ GME.0000000000001040

33. Arnot M, Emmott E, Mace R. The relationship between social support, stressful events, and menopause symptoms. PLoS One. 2021;16 (1):1-17. doi:10.1371/journal.pone.0245444

34. Reyes-Tovilla J, Hernandez H, Juarez I, et al. Psychological evaluation of impulsive/premeditated aggression and associated factors: a cross-sectional study in users of health services in Tabasco, Mexico. Salud Ment. 2016;39(1):19.24. doi:10.17711/SM.0185-3325.2015.064

35. Afridi I. Psychological and social aspects of menopause. In: A Multidisciplinary Look at Menopause. 2017. doi:10.5772/ intechopen.69078

36. Patruno D, Manzo Z, González Blanco M. Depresión en la perimenopausia y en la posmenopausia. Rev Obs Ginecol Venez. 2016;76 (3):173-181.

37. Carranza-Lira S, Palacios-Ramirez M. Frecuencia de depresión en mujeres premenopáusicas y posmenopáusicas. Rev Med Inst Méx Seguro Soc. 2019;56(6):533-536.

38. Gross JJ, John OP. Individual differences in two emotion regulation processes: implications for affect, relationships, and well-being. J Pers Soc Psychol. 2003;85(2):348-362. doi:10.1037/0022-3514.8 5.2 .348

39. Astin JA. Why patients use alternative medicine: results of a national study. J Am Med Assoc. 1998;279(19):1548-1553. doi:10.1001/ jama.279.19.1548

40. Silva CS, Agudelo DM. Creencias sobre la enfermedad y estrategias de afrontamiento como predictores de la calidad de vida en pacientes en rehabilitación cardiovascular. Acta Colomb Psicol. 2011;14(1):47-60.

41. Aldwin C. Stress, Coping, and Development: An Integrative Perspective. 2nd ed. Guilford Press; 2008. doi:10.1177/ 1534765608315624

42. Duarte FG, Da Silva Moreira S, Almeida MDCC, et al. Sex differences and correlates of poor glycaemic control in type 2 diabetes: a cross-sectional study in Brazil and Venezuela. BMJ Open. 2019;9: e023401. doi:10.1136/bmjopen-2018-023401 


\section{Publish your work in this journal}

Psychology Research and Behavior Management is an international, peer-reviewed, open access journal focusing on the science of psychology and its application in behavior management to develop improved outcomes in the clinical, educational, sports and business arenas. Specific topics covered in the journal include: Neuroscience, memory and decision making; Behavior modification and management; Clinical applications; Business and sports performance management; Socia and developmental studies; Animal studies. The manuscript management system is completely online and includes a very quick and fair peer-review system, which is all easy to use. Visit http://www. dovepress.com/testimonials.php to read real quotes from published authors. 